\title{
Functional electrical stimulation reinforced tenodesis effect controlled by myoelectric activity from wrist extensors
}

\author{
Rune A. Thorsen, MSc, PhD; ${ }^{1 *}$ Eugenio Occhi, MD; ${ }^{2}$ Silvano Boccardi, MD; ${ }^{1}$ Maurizio Ferrarin, MSc, PhD $^{1}$ \\ ${ }^{1}$ Centro di Bioingegneria-FDG, Fondazione Don Carlo Gnocchi Onlus IRCCS, Milano, Italy; ${ }^{2}$ The Spinal Unit, \\ Azienda Ospedaliera E. Morelli, Sondalo (SO), Italy
}

\begin{abstract}
We demonstrated a method for enhancing the tenodesis grip in individuals with sustained tetraplegia with spinal cord lesion at the C6-C7 neurological level. Subjects used the myoelectric activity from wrist extensor muscles to directly control the electrical stimulation of the extrinsic finger and thumb flexors (flexor pollicis longus and flexor digitorum superficialis/profondus) with the use of a specially designed system, Myoelectrically Controlled Functional Electrical Stimulation (MeCFES). We screened 20 medical records and selected 9 subjects. Of the nine subjects, five showed a positive response to the surface stimulation and could test the system; the other four failed to achieve functional finger flexion because of skin sensitivity or inadequate movement. We evaluated hand function, with and without the MeCFES system, using tests involving three everyday objects: manipulating a videocassette with the key grip, drinking from a bottle with the palmar grasp, and writing with a pen using the tripod grip. Without the system, none of the five subjects could complete all three tasks; but, when assisted with MeCFES, all subjects completed all the tasks. The system proved simple and intuitively easy to use, and no training was needed for subjects to obtain immediate functionality. We will need further research to evaluate the usefulness of the system in activities of daily living.
\end{abstract}

Key words: EMG control, FES, functional electrical stimulation, hand function, myoelectric signals, rehabilitation, tetraplegia.

\section{INTRODUCTION}

In the rehabilitation of people with tetraplegia resulting from spinal cord lesion at the C6-C7 neurological level, the recovery of hand function is a major objective [1]. In many cases, finger flexion is compromised to such an extent that patients cannot perform activities of daily living (ADLs) that require the grasping and holding of objects.

Early treatment is aimed at promoting the tenodesis effect (passive finger flexion in response to wrist extension). Orthotic splinting of the hand into a fixed position is commonly used to shorten the soft tissue in flexion and hence make wrist extension more likely to generate strong finger grasp [1]. Success in providing a person with lateral grip (key grip) and/or palmar grasp depends on voluntary wrist extension, as well as on the length and elastic tension of the finger flexors. If inadequate passive finger flexor action exists for grasping, one can use orthotic splinting or prehensile tools to help patients perform ADLs such as eating, drinking, writing, and manipulating

\footnotetext{
Abbreviations: ADL = activity of daily living, ECR = extensor carpi radialis longus/brevis, FDP = flexor digitorum profundus, FDS = flexor digitorum superficialis, FES = functional electrical stimulation, FPL $=$ flexor pollicis longus, $I_{\max }=$ maximum current amplitude, IP = interphalangeal, MeCFES = Myoelectrically Controlled Functional Electrical Stimulation, MES = myoelectric signal, MRC = Medical Research Council, $\mathrm{PWL}=$ piecewise linear.

*Address all correspondence to Rune Thorsen, PhD; Centro di Bioingegneria, Fond. Don Carlo Gnocchi ONLUS IRCCS, via Capecelatro, 66, I-20148 Milano, Italy; 390240308305; fax: 39-024048919.
}

Email: rthorsen@cbi.dongnocchi.it

DOI: 10.1682/JRRD.2005.04.0068 
objects. In addition, surgical procedures can be used to transfer active muscles or shorten tendons to improve grasp force [2-5]. However, some patients prefer noninvasive methods to improve hand function.

Functional electrical stimulation (FES) can be used to artificially induce the muscle contraction of innervated muscles, triggering action potentials in the motor nerve [6]. A prerequisite for FES is that the secondary motor neuron has been spared by the lesion, because the nerve is more easily stimulated than muscle fibers [6]. Among the most promising devices used to aid in the restoration of hand function in people with sustained tetraplegia are the implanted Freehand ${ }^{\mathrm{TM}}$ system [7-10] and the noninvasive Handmaster ${ }^{\mathrm{TM}}$ [11-12]. The Freehand ${ }^{\mathrm{TM}}$, an implanted multichannel stimulation system controlled by contralateral shoulder movements detected through an external sensor, has been proven functional in multicenter clinical studies [8-10]. The Handmaster ${ }^{\mathrm{TM}}$ is a forearm splint that holds the wrist in a fixed position. It houses five surface electrodes that stimulate the thumb and finger flexors and extensors, providing exercise and grasp functions. The stimulation system is controlled by a portable electronic unit, and users push a button to trigger preprogrammed stimulation sequences for hand opening and grasping [11-12].

How the FES is controlled is an important issue. It should be intuitively easy to use, and the control strategy should not interfere with or limit other residual voluntary movements. Volitional wrist extension is synergistic with grasping and has proven a feasible control method [13]. Wrist extension can be sensed by a position transducer to help users accurately and reliably control stimulation [14], but position control does not discriminate between active and passive wrist flexion/extension. This can make grasp of heavy objects difficult to maintain if the user pulls the wrist into flexion. The myoelectric signal (MES) has a poor information content [15] but has proven useful for controlling commercially available prostheses [16-17]. Furthermore, MES has been demonstrated feasible for FES control in the laboratory [13,1823]. A few devices are already on the market that use MES to trigger electrical stimulation with a preset duration [24-26]. Such devices are intended for muscle reeducation but are of limited use as an orthotic aid, because the user has no direct control over the intensity or duration of the stimulation and is therefore not able to control the grasp force or release objects at will.
We devised a Myoelectrically Controlled Functional Electrical Stimulation (MeCFES) system, and have demonstrated that wrist extensor MES can directly control the stimulation of the same muscles to enhance the wrist extension in individuals with tetraplegia under volitional control [22]. This same method has been applied when thumb flexion is insufficient, allowing the wrist extension to control the stimulation of the flexor pollicis brevis and the adductor pollicis by placement of one electrode over the first dorsal interosseous and the other electrode over the ulnar nerve at the pisiform bone; the result is a functional lateral grip [23]. In this study of the feasibility of other simple-to-use configurations, we applied the system in a configuration in which the MES from the wrist extensors ECR (extensor carpi radialis longus/brevis) is used to control the FES of the FPL (flexor pollicis longus) and the finger flexors FDS/FDP (flexor digitorum superficialis/profondus). Surface stimulation will most likely recruit the FDS first because of its superficial position, but no distinction will be made between FDS and FDP because of their functional similarity; i.e., both cause flexion of the metacarpophalangeal and proximal interphalangeal (IP) joints.

\section{METHODS}

Subjects were recruited from The Spinal Unit of the E. Morelli Hospital in Sondalo, Italy. The medical records of hospitalized patients were screened for the following inclusion criteria-

1. 18 to 60 years of age.

2. Clinically stable, at least 1 year postinjury.

3. C6-C7 neurological level American Spinal Injury Association classification A, Group 2-3-4-5 according to the International Classification for Surgery of the Hand in Tetraplegia.

4. Active shoulder and elbow control, pronation/supination. Wrist extension of at least grade 4 on the Medical Research Council (MRC) scale.

5. No contraindications for stimulation (hypotension, cardiovascular problems, pacemaker, epilepsy, etc.).

6. No spasticity of the hand muscles $(<2$ on the Ashworth scale).

All subjects gave informed consent for the study, which was approved by the local ethics committee and adhered to the guidelines established in the Declaration 
of Helsinki. The MeCFES system was applied if the subject complied with a further inclusion criterion: one channel of FES applied to the FPL and FDS/FDP should produce a force, without causing discomfort, corresponding to grade 4 on the MRC muscle scale. The resulting movement should be adequate for grasping.

The MeCFES system consisted of an amplifier, a signal processor, and a single-channel stimulator. The system was developed for homologous stimulation (stimulation of the same muscle from which the MES is recorded), so its hardware design was optimized to reduce noise in the amplified MES caused by the stimulation (stimulation artifacts). The amplifier [27] was directcurrent coupled with automatic offset compensation to avoid transients from the stimulation. To reject the $\mathrm{M}$ waves, we set the first $10 \mathrm{~ms}$ of the sampled signal to zero after the stimulation pulse. Comb filtering with a transformed first-order finite impulse response filter reduced the harmonics of stimulation responses, and the root-mean-square over the stimulation interval was calculated. We applied a first-order infinite impulse response low-pass filter with a cutoff frequency of $1 \mathrm{~Hz}$ to obtain a smooth estimate of the myoelectric level. Stimulation amplitude was then computed as a piecewise linear (PWL) function (Figure 1) of the myoelectric level. The PWL function limited the stimulation to a maximum current amplitude $\left(I_{\max }\right)$ to avoid overstimulation and defined the coefficient between the myoelectric level and the stimulation amplitude (gain). A consequence of this "proportional" control is that the subject has to sustain activation of the controlling muscle (ECR) to maintain a stimulation output. In the case of muscle fatigue, the subject has to compensate by increasing ECR activation until $I_{\max }$ is reached. The stimulation pulses consisted of biphasic $300 \mu$ s rectangular impulses with a $300 \mu$ s interphase interval and a 16.6 pps fixed repetition rate. The dimensions of the prototype (Figure 2) were $11 \mathrm{~cm}$ wide $\times 4 \mathrm{~cm}$ high $\times 6 \mathrm{~cm}$ deep, it weighed $200 \mathrm{~g}$, and the system could be powered by a standard $9 \mathrm{~V}$ battery running for at least $5 \mathrm{~h}$ of continuous $100 \mathrm{~mA}$ stimulation. A personal computer could be connected as a master control of the system, enabling us to change the stimulation parameters and view the MES.

The stimulation electrodes (PALS, Axelgaard, Fallbrook, California) were placed on the skin, medially on the anterior part of the forearm, over the motor points of the FDS/FDP and FPL. We used a pushbutton-operated stimulator (ODFS, Salisbury District Hospital, Salisbury,

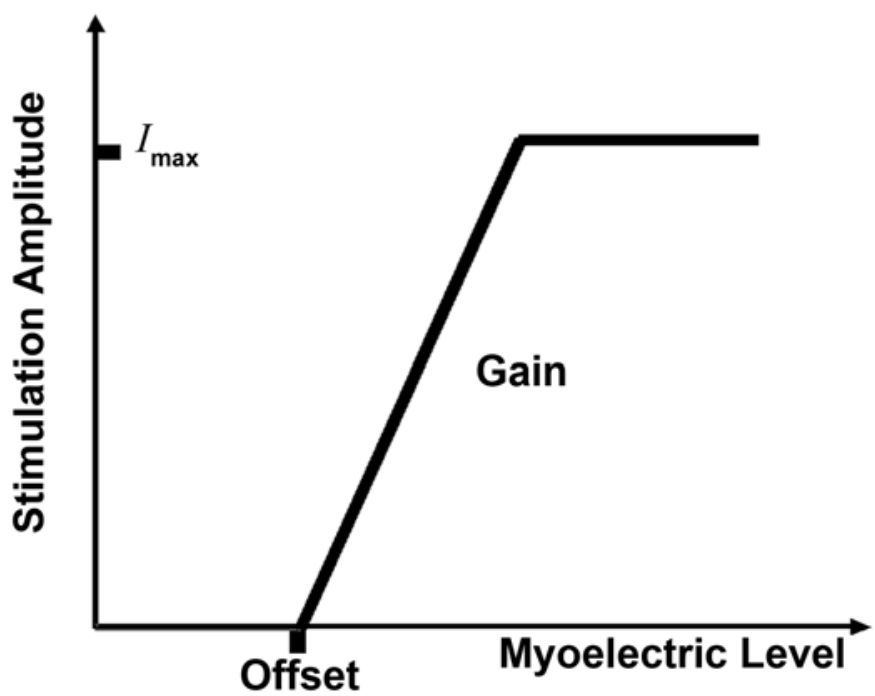

Figure 1.

Piecewise linear function defined by offset, gain, and maximal stimulation $\left(I_{\max }\right)$ that defines relation between myoelectric level and stimulation amplitude.

England) to test muscle response and locate the electrode position that gave the best finger and thumb flexion for grasping. Recording electrodes (Medicotest A/S, Denmark) were placed on the skin over the muscle belly of the ECR distal to the radiohumeral joint (Figure 3) and the neutral (ground) electrode over the olecranon.

\section{Procedure}

We found the stimulation parameters in the following order: first we found the stimulation amplitude $I_{\max }$, then iteratively adjusted gain and offset. We defined maximum stimulation by increasing the stimulation amplitude to the point where sufficient muscle contraction was produced or the subject felt an unpleasant sensation (whichever came first). We then set the offset to the myoelectric level of relaxed wrist extensors. Thereafter, we increased the gain with the subject providing full wrist extension until output reached $I_{\max }$. Since stimulation interferes with the MES, creating a noise component in the myoelectric level, we had to iteratively optimize offset and gain until the patient was able to control the system smoothly.

To evaluate the effectiveness of grasping with and without the MeCFES, we chose the following tests: (1) using lateral grip to pick up a videocassette, move it over an obstacle (a bottle), and release it; (2) using the palmar grasp to pick up a half-liter plastic bottle $(20 \mathrm{~cm}$ high, $6 \mathrm{~cm}$ diameter, $0.5 \mathrm{~kg}$ ) of mineral water and drink 


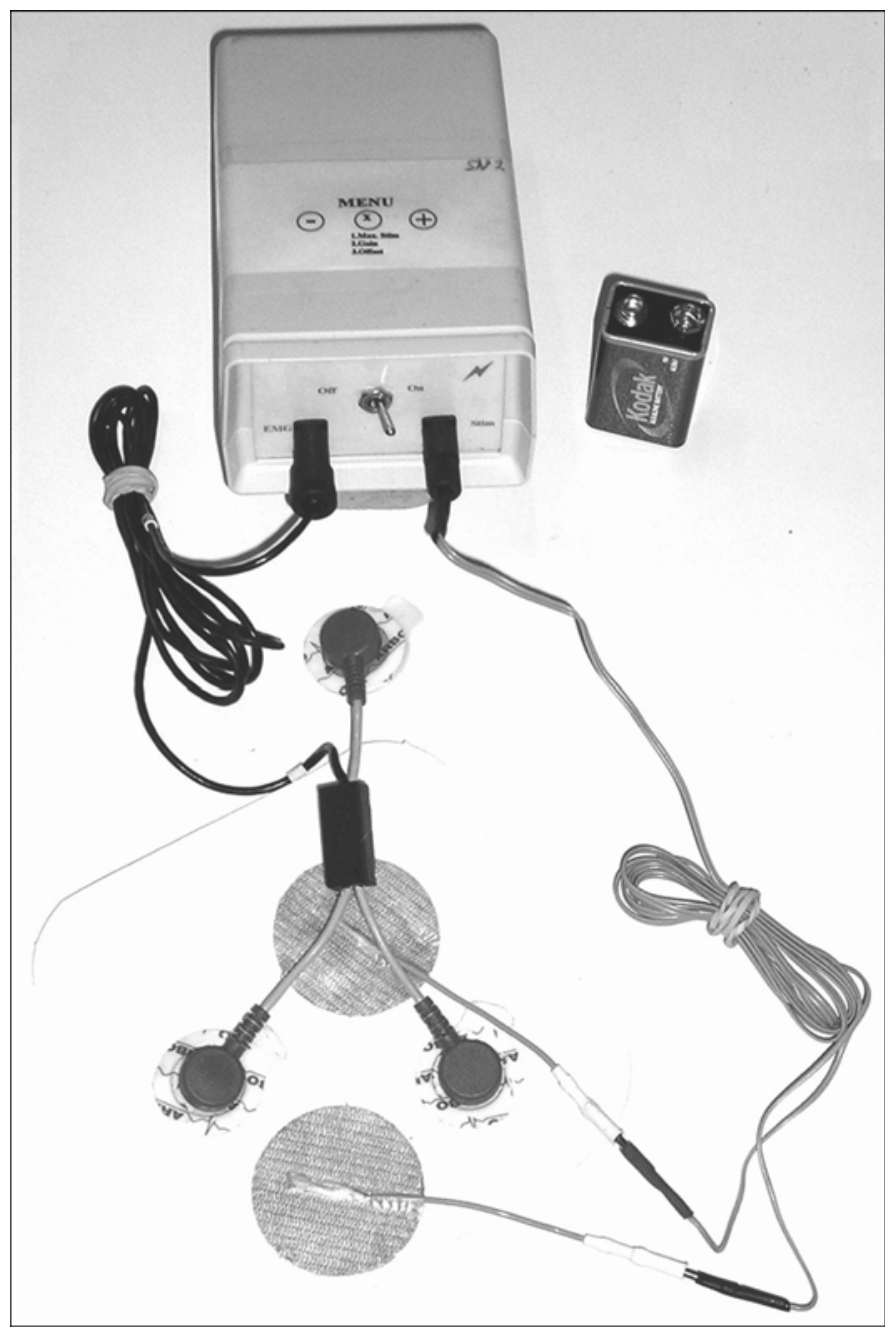

Figure 2.

Myoelectrically Controlled Functional Electrical Stimulation with cables and electrodes in its $9 \mathrm{~V}$ battery version. (a)

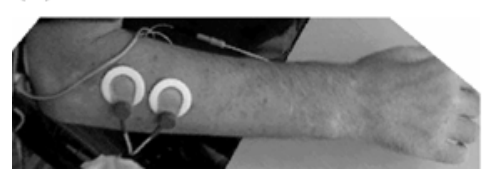

(b)

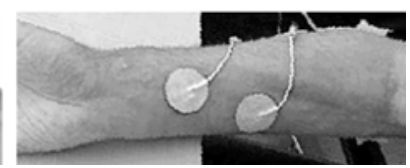

Figure 3.

Placement of recording (a) electrodes and (b) stimulation electrodes.

it; (3) using the tripod grip to pick up a thick pen $(2 \mathrm{~cm}$ diameter) and write (only in the case where the dominant hand was stimulated). These three basic grasps were chosen even though the stimulation did not create different grasping patterns, because they are often in the objectives of restoring grasp function [2-5,7-11,13-14,18-21]. The subjects sat upright in their wheelchairs in front of a normal table and were asked to use only the tested hands. The objects were placed in turn on the table in front of the tested hands. The videocassette was placed in an upright position with the long edge parallel to the subject's sagittal plane, aligned with the shoulder, and the task was for the subject to grasp the videocassette without knocking it over, to lift it over the bottle (placed in front of his midline), and to leave it on the other side. Subjects were to take the bottle from its position without knocking it over, lift it to their mouths as if to drink from it (cap kept on), and then put it down. The pen was placed flat on the table on a piece of paper, and the task was for the subject to pick it up using the tripod grip, to put it to the paper, and to release it onto the table again. We allowed $10 \mathrm{~s}$ for each task to be completed (duration of drinking or writing excluded). Exceeding the time limit revealed the task to be difficult for the subject. To avoid stressing the subjects, we did not inform them of the time limit. The type of grasp and the required action was demonstrated by the examiner before the test, so that the task and normal speed would be clear to the subject. The test was carried out once as a practice run and then repeated once each, with and without stimulation. Video recording was used for calculation of the scores.

\section{Scoring System}

For scoring purposes, we divided each task into four states: enfolding the object, applying sufficient grasp force to lift it, maintaining sufficient grasp force to manipulate the object and, finally, releasing the object in a controlled manner. Each task was given a score on a 5-point scale, from 0 to 4 as follows:

0 . Unable to enfold the object.

1. Able to enfold the object, but with insufficient grip strength to lift it.

2. Grasping but not manipulating.

3. Taking the object and completing the task, but failing to release the object properly.

4. Functional grasp and release enabling completion of the task within $10 \mathrm{~s}$.

When the time limit was exceeded, scoring stopped at the stage corresponding to the time limit. In the case of a short corrective movement with the other hand, the score was marked with an asterisk. In addition to the 
tests, the subjects were asked about their opinion of the system in an informal interview.

\section{RESULTS}

Of 20 medical records screened, 9 subjects were found to comply with the inclusion criteria. All the included subjects had sensation in the stimulated area. Testing the response to FES excluded four subjects; in three of these, the contraction force was insufficient at $I_{\max }$ (i.e., in the comfortable range of stimulation intensity that does not cause pain), and in one subject, the thumb flexed into the palm with weak finger flexion. In the remaining five subjects (Table 1), we were able to find an electrode placement that gave flexion of both index finger and thumb (Figure 3). The position of the

\section{Table 1.}

Five tested male subjects with neurological level of lesion according to American Spinal Injury Association scale. In 1 subject, both hands were tested; in other 4, only 1 hand fell within inclusion criterion and was considered. Following key muscles were present below elbow with at least grade 4 according to Medical Research Council: brachioradialis, extensor carpi radialis brevis and longus, and pronator teres.

\begin{tabular}{ccccc}
\hline Subject & $\begin{array}{c}\text { Neurological } \\
\text { Level }\end{array}$ & $\begin{array}{c}\text { Tested } \\
\text { Hand }\end{array}$ & $\begin{array}{c}\text { Years Since } \\
\text { Injury }\end{array}$ & Age \\
\hline A & C6-C7 & R, L & 2 & 45 \\
B & C6-C7 & R & 5 & 26 \\
C & C6 & R & 7 & 30 \\
D & C6 & L & 3 & 24 \\
E & C7 & R & 3 & 42 \\
\hline R = right & & & & \\
L = left & &
\end{tabular}

distance between the electrodes ranged from 2 to $4 \mathrm{~cm}$ (edge to edge).

The subjects immediately understood how to operate the system and, apart from adjusting the system parameters for each subject, we provided no training before subjects used the system. Table 2 shows the scores with and without the application of the MeCFES for the five subjects: for all subjects, the range of wrist movement was normal but the tenodesis effect was weak.

Subject A (C6-C7 neurological level) had similar right- and left-hand capacity. Without the system, he could place the hand so that the videocassette was between thumb and index finger, but he had insufficient force in thumb flexion and adduction to lift the videocassette free of the table. Flexion of the proximal IP joints was weak, and he was unable to hold the bottle with sufficient force to lift it. Enfolding these two objects without lifting yielded Subject A a score of 1 for both hands. He was unable to enfold the pen or hold it with a tripod grip; hence his score on the test was zero. Assisted by the MeCFES system, he was able to complete both the videocassette and the bottle tasks with each hand (4 points) (Figure 4), and with the right (dominant) hand he could pick up the pen and write; although due to a lack of dexterity, he had to correct the pen position by pushing with his left hand before writing. The left (nondominant) hand was not tested for writing. For both hands, the stimulation gave Subject A a firm flexion of the fingers and an adduction of the thumb that was sufficient to hold the objects with a secure grasp. In addition, with two MeCFES systems

electrodes varied from one subject to another, and the

Table 2.

Scores for six tested hands of five subjects (Subject A was tested bilaterally). For each column, score on left (Natural) is without Myoelectrically Controlled Functional Electrical Stimulation (MeCFES); score on right is with use of MeCFES. Mean score for all hands is 1.7 without system and 4 with system.

\begin{tabular}{|c|c|c|c|c|c|c|c|}
\hline \multirow{2}{*}{ Subject } & \multirow{2}{*}{ Hand } & \multicolumn{2}{|c|}{ Videocassette } & \multicolumn{2}{|c|}{ Bottle } & \multicolumn{2}{|c|}{ Writing with Pen } \\
\hline & & Natural & MeCFES & Natural & MeCFES & Natural & MeCFES \\
\hline A & $\overline{\mathrm{R}}$ & 1 & 4 & 1 & 4 & 0 & $4^{*}$ \\
\hline A & $\mathrm{L}$ & 1 & 4 & 1 & 4 & NA & NA \\
\hline B & $\mathrm{R}$ & 3 & 4 & 2 & 4 & 1 & 4 \\
\hline $\mathrm{C}$ & $\mathrm{R}$ & 1 & $4^{*}$ & 1 & $4^{*}$ & NA & NA \\
\hline $\mathrm{D}$ & $\mathrm{L}$ & 1 & 4 & 4 & 4 & NA & NA \\
\hline $\mathrm{E}$ & $\mathrm{R}$ & 2 & 4 & 2 & 4 & 4 & 4 \\
\hline
\end{tabular}



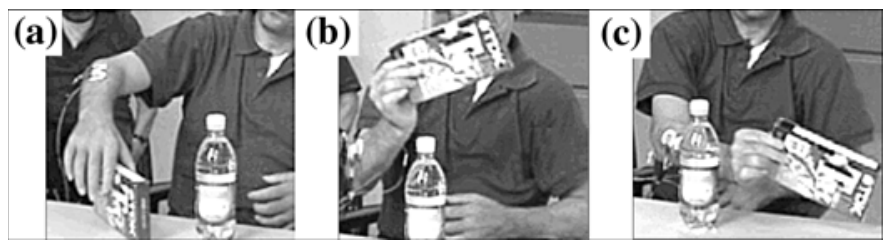

Figure 4.

Subject A (a) picking up, (b) moving, and (c) releasing videocassette.

mounted bilaterally, he opened the bottle of water, holding it with one hand and turning the cap with the other. Likewise, on his own initiative, he took an espresso coffee in a thin (1 mm) plastic cup and drank it.

Subject B had excessive flexion of the distal IP joint of the index finger of the right hand, so we splinted this joint with a piece of tape to stiffen it at $10^{\circ}$. Without the MeCFES system, Subject B was able to use the key grip to pick up the videocassette, but it tended to slip and he dropped it rather than put it down (3 points). Because of the difficulty Subject B had in picking up the object and holding it firmly, he reached the time limit before he put the object down. Subject B was able to hold the bottle by light supination of the hand and hyperextension of the wrist, thus balancing the bottle rather than grasping it; he could not bring the bottle to his mouth for drinking (2 points) because it slipped from his hand. He was unable to pick up the pen ( 0 points). With the MeCFES system, Subject B gained a firmer lateral grip, moving the videocassette over the bottle and leaving it in good order, without difficulty and within the time limit (4 points). When taking the bottle, he used the normal palmar grasp to bring the bottle to his mouth without compensation (4 points); the MeCFES also enabled him to complete the writing task with the tripod grip (4 points).

Without the MeCFES system, Subject C used an alternative grasp to lift the videocassette. He squeezed the object between the second and third fingers and thus performed the task without using the key grip. One point was given when the subject demonstrated that he could (using the lateral grip position) place his hand around the videocassette, although he could not lift it. He could only enfold the bottle, but not lift it off the table with the palmar grasp (1 point), although by using both hands, he was able to enfold and lift it (Figure 5). With the system he gained a firmer grasp, allowing him to manipulate the videocassette with the key grip (4 points) and to grasp, hold, and bring the bottle to his mouth, although with some difficulty (4 points). In both cases he used his left hand briefly to push the object further into his hand, hence an asterisk is added after his score in Table 2 . This use of the left hand was probably more the result of habitually using both hands rather than out of necessity. The subject was left-handed, and therefore, the writing test was not performed.

For Subject D, his right hand was functional so his left hand was tested. Without the system, he was able to enfold the videocassette with the lateral grip, but he had insufficient force to lift it off the table (1 point). He was able to grasp the bottle and drink from it (4 points) without stimulation. With MeCFES, his key grip became sufficiently strong to let him take and manipulate the videocassette (4 points), and handle the bottle with a firm grip (4 points). The writing task was omitted because it was not his dominant hand.

Subject E had a medium/good tenodesis effect of his right hand, and he performed the tasks with little difficulty, although he balanced the videocassette in his hand rather than grasping it (2 points), thus he was unable to lift the videocassette over the obstacle without dropping

(a)

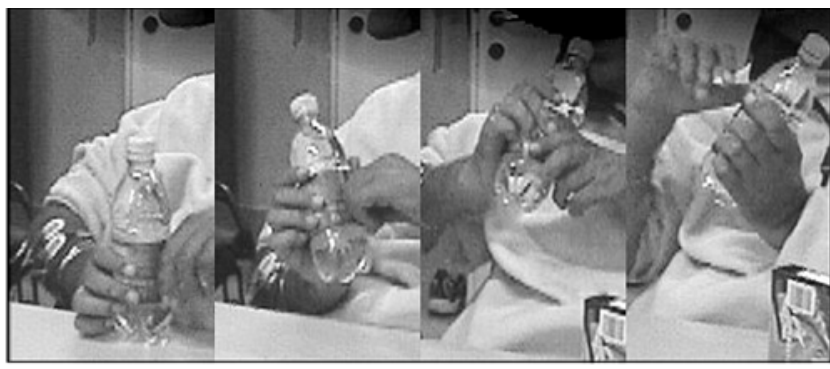

(b)

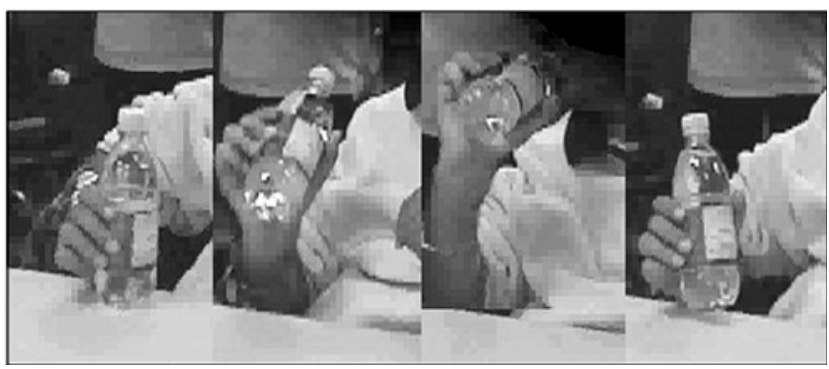

Figure 5.

Subject C drinking from bottle: (a) Without Myoelectrically Controlled Functional Electrical Stimulation (MeCFES), he needs to use left hand to lift bottle off table and thus scores only 1 point. He spontaneously uses left hand, which was stronger, to put down bottle. (b) With MeCFES he can grasp bottle and lift it to his mouth for drinking, as well as put it down properly. He briefly used left hand to ensure his grasp before lifting bottle off table. 
it. For the palmar grasp, he was able to lift the bottle off the table, but he did not have enough grip strength to hold it to his mouth (2 points). With the MeCFES, he completed both tasks, although with some difficulty (4 points each). He completed the writing task (4 points) with and without the MeCFES, and he reported that the stimulation was more of a hindrance than a help.

\section{DISCUSSION}

All the subjects immediately understood how to use the system, which proves the method to be intuitive and simple. We mounted and tuned the system in less than 15 min for the five participating subjects (A-E); whereas for the four dropouts, we spent up to 30 min before giving up on obtaining the desired finger flexion. The system did not appear to influence the strategies the subjects used to enfold or release the objects with respect to the natural tenodesis effect. That the system enabled the subjects to gain a higher score in the hand function test means that the system effectively increases the tenodesis grip force to a sufficient level to perform the considered ADLs. When we asked the subjects whether they would like to use the system daily, we got a very definite positive answer from Subject A. Subjects C and D, who were tested only on the nondominant hand, were uncertain; they were less motivated because of the difficulty with electrode placement. Subject B did not like the "feel" of the stimulation and preferred not to depend on any aids. Subject E felt he had only a slight advantage from the system and thought he would probably use the system only occasionally.

Careful evaluation is needed for one to select patients who can benefit from the system. Besides the neurological condition and functional abilities, one must test muscle response to FES and ensure that the resulting movement is adequate for grasping. The stimulation should produce a muscle force above grade 3 without being uncomfortable for the subject. Some subjects found the sensation unpleasant at the stimulation intensities needed to induce powerful contractions, and in some subjects, one channel was not sufficient to generate a correct synchronized flexion of the fingers.

To keep the system simple and the electrode count low, we decided to use only one channel for control and stimulation. This limits the possible grip types and grasping pattern. One subject was excluded because obtaining the necessary balance between FPL and FDS/FDP with only one channel was not possible. Although such a test was not included in the protocol, this muscular imbalance could probably be resolved by stimulating the two muscles separately. Thus, possible interference between multiple channels needs further examination. As in the case of a functional tenodesis effect, grasping must be performed in a specific way; e.g., the bottle is approached from the top so that the hand is opened by sliding over the cone shaped top of the bottle, or the videocassette is taken from the top with a pronated hand to let gravity flex the wrist and extend the fingers. Likewise, with only one channel for stimulation, active finger extension is not augmented.

Under certain circumstances, an MES-controlled FES system can display instability. Some reasons for this are insufficient stimulation artifact rejection in the electronics, mono- and polysynaptic reflexes, and the F-wave [28], which can present a significant noise component. In the present study, the combination of system design, careful electrode placement, and parameter adjustment were sufficient to avoid the instability problem.

Daily use of the MeCFES would require the user or caregiver to apply the electrodes and make daily adjustments to the $I_{\max }$, gain, and offset parameters. Methods to facilitate these requirements still need to be developed. The issue of long-term use must be evaluated, and our research is being directed toward an evaluation of the use of the system in daily life.

\section{CONCLUSION}

We used a myoelectrically controlled single-channel surface FES system that allows the user to proportionally control the stimulus intensity to reinforce the tenodesis grip in subjects with C6-C7 tetraplegia. The subjects had active wrist extension, but finger flexion in the tenodesis grasp was weak or insufficient. Using the MES from the wrist extensor muscles (ECR) to directly control stimulation of the long thumb and finger flexors resulted in the subjects' immediate improvement of functional grasping capability, allowing the manipulation of common objects (a bottle, a videocassette, and a pen) in the five subjects tested. The results obtained and the limited invasiveness of MeCFES warrant further research, and the system should be proposed to selected patients as a supplement or alternative to existing treatments and aids. 


\section{ACKNOWLEDGMENTS}

We wish to thank the patients who participated in the study.

This material was based on work supported by the European Union as part of the Human Potentials Project, "NeuralPro contract HPRN-CT-2000-00030," and the Italian Ministry of Health, "Ricerca Corrente."

The authors have declared that no competing interests exist.

\section{REFERENCES}

1. Bromley I. Tetraplegia and paraplegia: A guide for physiotherapists 5th ed. London (England): Churchill Livingstone; 1998. p. 25-29.

2. Allieu Y, Coulet B, Chammas M. Functional surgery of the upper limb in high-level tetraplegia: Parts I and II. Tech Hand Up Extrem Surg. 2000;4(1):50-68.

3. Freehafer AA, Kelly CM, Peckham PH. Tendon transfer surgery for the restoration of upper limb function after a cervical spinal cord injury. J Hand Surg [Am]. 1984; 9(6):887-93. [PMID: 6512207]

4. House JH, Walsh TE. Two stage reconstruction of the tetraplegic hand. In: Strickland JW. The hand (Master techniques in orthopaedic surgery) Philadelphia (PA): Lippincott Williams \& Wilkins; 1998.

5. Moberg E. The present state of surgical rehabilitation of the upper limb in tetraplegia. Paraplegia. 1987;25(4):351-56. [PMID: 3627823]

6. Baker PT, McNeal DR, Benton LA, Bowman RL, Waters LL. Neuromuscular electrical stimulation: A practical guide. 3rd ed. Downey (CA): Rancho Los Amigos Medical Center; 1993. p. 135-40.

7. Keith MW, Peckham PH, Thrope GB, Stroh KC, Smith B, Buckett JR, Kilgore KL, Jatich JW. Implantable functional neuromuscular stimulation in the tetraplegic hand. J Hand Surg [Am]. 1989;14(3):524-30. [PMID: 2786897]

8. Taylor P, Esnouf J, Hobby J. The functional impact of the Freehand System on tetraplegic hand function. Clinical Results. Spinal Cord. 2002;40(11):560-66.

[PMID: 12411963]

9. Peckham PH, Keith MW, Kilgore KL, Grill JH, Wuolle KS, Thrope GB, Gorman P, Hobby J, Mulcahey MJ, Carroll S, Hentz VR, Wiegner A, Implantable Neuroprosthesis Research Group. Efficacy of an implanted neuroprosthesis for restoring hand grasp in tetraplegia: A multicenter study. Arch Phys Med Rehabil. 2001;82(10):1380-88.

[PMID: 11588741]

10. Kilgore KL, Peckham PH, Keith MW, Montague FW, Hart RL, Gazdik MM, Bryden AM, Snyder SA, Stage TG. Dura- bility of implanted electrodes and leads in an upper-limb neuroprosthesis. J Rehabil Res Dev. 2003;40(6):457-68.

[PMID: 15077658]

11. Snoek GJ, IJzerman MJ, in 't Groen FA, Stoffers TS, Zilvold G. Use of the NESS handmaster to restore handfunction in tetraplegia: clinical experiences in ten patients. Spinal Cord. 2000;38(4):244-49. [PMID: 10822395]

12. NESS LTD. 19 Ha-Haroshet Street, PO Box 2500, Ra' anana 43654, Israel. (http://www.nessltd.com/)

13. Hart RL, Kilgore KL, Peckham PH. A comparison between control methods for implanted FES hand-grasp systems. IEEE Trans Rehabil Eng. 1998;6(2):208-18. [PMID: 9631329]

14. Prochazka A, Gauthier M, Wieler M, Kenwell Z. The bionic glove: An electrical stimulator garment that provides controlled grasp and hand opening in quadriplegia. Arch Phys Med Rehabil. 1997;78(6):608-14. [PMID: 9196468]

15. Vodovnik L, Rebersek S. Information content of myo-control signals for orthotic and prosthetic systems. Arch Phys Med Rehabil. 1974;55(2):52-56. [PMID: 4272626]

16. Motion Control, Inc, 2401 South 1070 West, Suite B, Salt Lake City, Utah, 84119-1555, USA

(http://www.utaharm.com)

17. Otto Bock HealthCare GmbH, Location Orthopedic Industry, Max-Näder-Str. 15, Germany (http://www.ottobock.de/ de/tgpat/products/arm_prosthesis/

myoelectrically_controlled)

18. Saxena S, Nikolic S, Popovic D. An EMG-controlled grasping system for tetraplegics. J Rehabil Res Dev. 1995; 32(1):17-24. [PMID: 7760263]

19. Muraoka Y, Miyajima S, Tomita Y, Honda S, Tanaka N, Okajima Y. EMG-controlled hand opening system for hemiplegia. In: Proceedings of the 6th Vienna International Workshop on Functional Electrostimulation: Basics, Technology, Application; 1998 Sep 22-24; Vienna (Austria). p. 225-28.

20. Rakos M, Freudenschuss B, Girsch W, Hofer C, Kaus J, Meiners T, Paternostro T, Mayr W. Electromyogram-controlled functional electrical stimulation for treatment of the paralyzed upper extremity. Artif Organs. 1999;23(5): 466-69. [PMID: 10378945]

21. Popovic MR, Keller T, Pappas IP, Dietz V, Morari M. Surface-stimulation technology for grasping and walking neuroprosthesis. IEEE Eng Med Biol Mag. 2001;20(1):82-93. [PMID: 11211664]

22. Thorsen R, Spadone R, Ferrarin M. A pilot study of myoelectrically controlled FES of upper extremity. IEEE Trans. Neural Syst Rehabil Eng. 2001;9(2):161-68.

[PMID: 11474969] 
23. Thorsen R, Ferrarin M, Spadone R, Frigo C. Functional control of the hand in tetraplegics based on residual synergistic EMG activity. Artif Organs. 1999;23(5):470-73. [PMID: 10378946]

24. Verity Medical LTD, Drove Road, Chilbolton, Hampshire SO20-6AD England (www.veritymedical.co.uk/)

25. Danmeter A/S, Kildemosevej 13, DK-5000 Odense C, Denmark (www.danmeter.dk/)

26. Stroke Recovery Systems, 8100 Southpark Way, Littleton, CO 80120, (www.biomation.com/neuromove900.htm)
27. Thorsen R. An artefact suppressing fast-recovery myoelectric amplifier. IEEE Trans Biomed Eng. 1999;46(6):764-66. [PMID: 10356884$]$

28. Thorsen R, Carpinella I, Ferrarin M. Can the F-response be volitionally repressed during functional electrical stimulation? Neuromodulation. 2005;8:141-45.

Submitted for publication April 12, 2005. Accepted in revised form September 7, 2005. 
